\title{
Аналіз стану ниркової гемодинаміки у хворих з первинним гіперальдостеронізмом за даними ультразвукового доплерівського сканування
}

\author{
А. О. Никоненко ${ }^{1}$, І. В. Зубрик ${ }^{1}$, О. О. Подлужний ${ }^{1}$, В. В. Якименко \\ 13апорізький державний медичний університет, \\ 23апорізька медична академія післядипломної освіти МОЗ України
}

\section{Analysis of the renal hemodynamics state in patients, suffering primary hyperaldosteronism in accordance to data of ultrasonographic Doppler scanning}

\author{
A. O. Nykonenko ${ }^{1}$, I. V. Zubryk ${ }^{1}$, O. O. Podluzhnyi ${ }^{1}$, V. V. Yakymenko ${ }^{2}$ \\ ${ }^{1}$ Zaporizhzhya State Medical University, \\ 2Zaporizhzhya Medical Academy of Postgraduate Education
}

Реферат

Мета. Проаналізувати стан ниркової гемодинаміки за даними ультразвукового доплерівського сканування у пацієнтів 3 первинним гіперальдостеронізмом (ПГА).

Матеріали і методи. У клініці госпітальної хірургії Запорізького державного медичного університету проведено лікування 52 хворих з ПГА. Ультразвукове доплерівське сканування ниркових артерій виконали 18 (34,6\%) пацієнтам.

Результати. У структурі відхилень на рівні стовбура ниркових артерій переважали зниження кінцево-діастолічної швидкості кровообігу, підвищення часу прискорення кровотоку та індексу резистентності, на рівні сегментарних та міжчасткових артерій - показники часу прискорення кровотоку, систоло-діастолічного співвідношення, індексу резистентності та пікового індексу. Встановлений кореляційний зв'язок між діастолічним артеріальним тиском та піковою систолічною швидкістю кровообігу на рівні міжчасткових артерій. Виявлена залежність між рівнем альдостерону та індексом резистентності на рівні стовбура ниркової артерії, систоло-діастолічним співвідношенням та середньою максимальною швидкістю кровотоку на рівні міжчасткової артерії.

Висновки. ПГА обумовлює зміни пікового індексу, індексу резистентності та систоло-діастолічного співвідношення на всіх рівнях розгалуження ниркових артерій. Рівень альдостеронемії корелює з індексом резистентності на рівні стовбура ниркової артерії, систоло-діастолічне співвідношення та середня максимальна швидкість кровотоку - на рівні міжчасткових артерій.

ключові слова: первинний гіперальдостеронізм; ниркова гемодинаміка; ультразвукове дослідження; індекс резистентності; піковий індекс.

Abstract

Objective. To analyze a renal hemodynamics state in accordance to results of ultrasonographic Doppler scanning in patients, suffering primary hyperaldosteronism (PHA).

Materials and methods. In the Clinic of Hospital Surgery of the Zaporizhzhya State Medical University the treatment of 52 patients, suffering PHA, was conducted. Ultrasonographic Doppler scanning of renal arteries was performed in 18 (34.6\%) patients Results. In a structure of deviations on the level of the renal arteries stem the lowering of a termino-diastolic velocity of the blood circulation, the time raising for the blood flow acceleration and for the resistance index, and on level of segmental and interlobar arteries - the time indices for the blood flow acceleration, of a systolo-diastolic ratio, the resistance the peaked indices have prevailed. Correlative link was established between diastolic arterial pressure and the peak systolic velocity of the blood circulation on level of interlobar arteries. Dependence between level of aldosterone and the resistance index on the renal artery stem level, systolic-diastolic ratio and median maximal velocity of the blood flow on the level of interlobar artery were established. Conclusion. PHA causes changes in the peak index, the resistance index and systole-diastolic ratios on all levels of the renal arteries branchings. The aldosteronemia level correlates with the resistance index on the level of a renal artery stem, systolicdiastolic ratio and median maximal velocity of the blood flow on level of interlobar arteries.

Keywords: primary hyperaldosteronism; renal hemodynamics; ultrasonographic investigation; index of resistance; peaked index.

Первинний гіперальдостеронізм (ПГА) обумовлює розвиток симптоматичної артеріальної гіпертензії ендокринного генезу та становить до 15\% в загальній структурі причин артеріальної гіпертензії і до 20\% - резистентної артеріальної гіпертензії [1 - 3].

Останніми роками у наукових колах зростає інтерес до вивчення особливостей ниркової гемодинаміки у хворих з ПГА. Це уможливить оцінити в динаміці результа- ти та більш об'єктивно ефективність проведеного хірургічного та консервативного лікування. Особливістю змін ниркової гемодинаміки, викликаних ПГА, є вплив підвищеного артеріального тиску (АТ) та рівня самого альдостерону на судинну стінку [4 - 6].

Мета дослідження: проаналізувати показники ниркової гемодинаміки за даними ультразвукового доплерівського сканування у пацієнтів з ПГА на діагностичному етапі. 


\section{Матеріали і методи дослідження}

За період з 2014 по вересень 2018 р. в клініці госпітальної хірургії Запорізького державного медичного університету на базі відділення трансплантації та ендокринної хірургії Запорізької обласної клінічної лікарні обстежено та проведено лікування 137 пацієнтів з патологією надниркових залоз.

ПГА діагностовано у 52 хворих. Дослідження ниркової гемодинаміки за допомогою ультразвукового доплерівського сканування проведено 18 (34,6\%) пацієнтам. Жінок було 11 (61,1\%), чоловіків - 7 (38,9\%). Середній вік хворих становив $(50,7 \pm 13,9)$ року.

Діагностику ПГА проводили згідно з клінічними практичними рекомендаціями з діагностики та лікування ПГА (Clinical Practical Guideline - The Management of Primary Aldosteronism, 2016).

Правобічну патологію надниркових залоз за даними комп'ютерної томографії виявили у 1 (5,6\%) пацієнта, лівобічну - у 10 (55,6\%), двобічну - у 7 (38,9\%).

Ультразвукове доплерівське сканування ниркових артерій проводили на ультразвуковому діагностичному доплерівському апараті «Philips En Visor HD» 3 використанням конвексного датчика з частотою 3,5 МГц (Philips, Нідерланди) зранку натще після стандартної підготовки в положенні пацієнта на спині, правому та лівому боці. У B-режимі сканування вивчали розміри, контур, ехогенність структури нирок. У режимі доплерівського кольорового картування оцінювали симетричність кровотоку в сегментах нирок, стан венозного відтоку, кровообіг в аорті, стан ниркових артерій та вен на наявність деформацій та порушення прохідності. За допомогою імпульсної доплерографії вимірювали реноаортальний індекс, пікову систолічну (Vps) та кінцево-діастолічну (Ved) швидкість кровообігу, систоло-діастолічне співвідношення (S/D), піковий індекс (PI) та індекс резистентності (RI), час прискорення потоку (АТ) та середню максимальну швидкість кровотоку (ТАМХ) на рівні ствола ниркових артерій, сегментарних і міжчасткових гілок.

Дані опрацьовували статистично за допомогою програми Statistica 6.0 (StatSoft, США, № AXXR712D833214FAN5). Відповідність виду розподілу ознаки закону нормального розподілу аналізували із застосуванням критері-

\begin{tabular}{|c|c|c|c|c|c|c|c|}
\hline \multirow{2}{*}{$\begin{array}{c}\text { Рівень } \\
\text { розгалуження } \\
\text { ниркової артерії }\end{array}$} & \multicolumn{7}{|c|}{ Доплерометричні показники } \\
\hline & Vps & Ved & S/D & $\mathrm{Pi}$ & $\mathrm{Ri}$ & AT & TAMX \\
\hline \multicolumn{8}{|l|}{ Стовбур } \\
\hline права нирка & $79,72 \pm 27,92$ & $26,18 \pm 8,69$ & $3,09 \pm 0,69$ & $1,16 \pm 0,25$ & $0,66 \pm 0,07$ & $\begin{array}{c}0,10 \\
0,08 ; 0,12)\end{array}$ & $44,01 \pm 14,21$ \\
\hline ліва нирка & $\begin{array}{c}78,00 \\
(56,00 ; 86,00)\end{array}$ & $25,12 \pm 8,64$ & $\begin{array}{c}2,80 \\
(2,50 ; 3,50)\end{array}$ & $1,15 \pm 0,30$ & $0,65 \pm 0,08$ & $0,10 \pm 0,04$ & $41,17 \pm 8,80$ \\
\hline \multicolumn{8}{|l|}{ Сегментарна } \\
\hline \multicolumn{8}{|l|}{ права нирка } \\
\hline $\mathrm{BC}$ & $47,43 \pm 19,51$ & $\begin{array}{c}14,00 \\
(11,00 ; 17,00)\end{array}$ & $3,30 \pm 0,78$ & $1,18 \pm 0,28$ & $0,67 \pm 0,08$ & $0,11 \pm 0,04$ & $\begin{array}{c}24,20 \\
(17,05 ; 31,95)\end{array}$ \\
\hline CC & $55,44 \pm 15,93$ & $18,62 \pm 7,29$ & $3,20 \pm 0,63$ & $1,16 \pm 0,22$ & $0,68 \pm 0,06$ & $0,10 \pm 0,03$ & $32,22 \pm 9,89$ \\
\hline $\mathrm{HC}$ & $44,87 \pm 14,91$ & $14,86 \pm 6,65$ & $3,17 \pm 0,81$ & $1,14 \pm 0,30$ & $0,67 \pm 0,09$ & $0,09 \pm 0,03$ & $25,97 \pm 9,47$ \\
\hline \multicolumn{8}{|l|}{ ліва нирка } \\
\hline $\mathrm{BC}$ & $46,75 \pm 14,52$ & $16,17 \pm 5,53$ & $\begin{array}{c}2,78 \\
(2,53 ; 3,32)\end{array}$ & $1,10 \pm 0,27$ & $0,65 \pm 0,08$ & $0,10 \pm 0,04$ & $25,83 \pm 6,01$ \\
\hline CC & $52,73 \pm 17,75$ & $18,78 \pm 7,92$ & $\begin{array}{c}2,70 \\
(2,31 ; 3,53)\end{array}$ & $1,08 \pm 0,29$ & $0,64 \pm 0,09$ & $\begin{array}{c}0,10 \\
(0,08 ; 0,15)\end{array}$ & $28,85 \pm 8,23$ \\
\hline $\mathrm{HC}$ & $43,48 \pm 11,90$ & $\begin{array}{c}13,50 \\
(11,00 ; 18,00)\end{array}$ & $290 \pm 1,03$ & $1,13 \pm 0,28$ & $0,65 \pm 0,08$ & $\begin{array}{c}0,08 \\
(0,07 ; 0,12)\end{array}$ & $24,27 \pm 6,23$ \\
\hline \multicolumn{8}{|l|}{ Міжчасткова } \\
\hline \multicolumn{8}{|l|}{ права нирка } \\
\hline $\mathrm{BC}$ & $31,25 \pm 13,59$ & $\begin{array}{c}10,00 \\
(7,00 ; 13,00)\end{array}$ & $3,03 \pm 0,64$ & $1,06 \pm 0,20$ & $0,65 \pm 0,07$ & $0,10 \pm 0,04$ & $18,67 \pm 8,14$ \\
\hline CC & $35,27 \pm 12,01$ & $12,61 \pm 4,66$ & $\begin{array}{c}2,78 \\
(2,71 ; 3,07)\end{array}$ & $1,02 \pm 0,37$ & $\begin{array}{c}0,64 \\
(0,63 ; 0,67)\end{array}$ & $\begin{array}{c}0,09 \\
(0,07 ; 0,11)\end{array}$ & $20,51 \pm 7,44$ \\
\hline $\mathrm{HC}$ & $29,45 \pm 9,17$ & $10,23 \pm 4,38$ & $\begin{array}{c}2,86 \\
(2,48 ; 3,35)\end{array}$ & $\begin{array}{c}1,05(0,92 \\
1,18)\end{array}$ & $0,65 \pm 0,10$ & $0,11 \pm 0,04$ & $17,38 \pm 5,67$ \\
\hline \multicolumn{8}{|l|}{ ліва нирка } \\
\hline $\mathrm{BC}$ & $30,09 \pm 6,21$ & $10,32 \pm 3,81$ & $\begin{array}{c}2,85 \\
(2,5 ; 3,33)\end{array}$ & $\begin{array}{c}1,07 \\
(0,94 ; 1,26)\end{array}$ & $0,65 \pm 0,09$ & $0,09 \pm 0,02$ & $16,56 \pm 3,71$ \\
\hline $\mathrm{CC}$ & $33,78 \pm 9,03$ & $11,97 \pm 4,73$ & $\begin{array}{c}2,75 \\
(2,55 ; 3,18)\end{array}$ & $1,06 \pm 0,25$ & $0,64 \pm 0,08$ & $0,10 \pm 0,04$ & $19,76 \pm 5,65$ \\
\hline $\mathrm{HC}$ & $27,43 \pm 9,91$ & $\begin{array}{c}10,0 \\
(7,00 ; 11,00)\end{array}$ & $\begin{array}{c}2,77 \\
(2,28 ; 3,48)\end{array}$ & $1,02 \pm 0,26$ & $0,64 \pm 0,09$ & $0,11 \pm 0,04$ & $14,91 \pm 3,27$ \\
\hline
\end{tabular}




\begin{tabular}{|c|c|c|c|c|c|c|c|c|c|c|c|c|c|c|}
\hline \multirow{3}{*}{$\begin{array}{l}\text { Рівень розгалуження } \\
\text { ниркової артерії }\end{array}$} & \multicolumn{14}{|c|}{ Доплерометричні показники } \\
\hline & \multicolumn{2}{|c|}{ Vps } & \multicolumn{2}{|c|}{ Ved } & \multicolumn{2}{|c|}{$S / D$} & \multicolumn{2}{|c|}{$\mathrm{Pi}$} & \multicolumn{2}{|c|}{$\mathrm{Ri}$} & \multicolumn{2}{|c|}{ AT } & \multicolumn{2}{|c|}{ TAMX } \\
\hline & абс. & $\%$ & абс. & $\%$ & абс. & $\%$ & абс. & $\%$ & абс. & $\%$ & абс. & $\%$ & абс. & $\%$ \\
\hline \multicolumn{15}{|l|}{ Стовбур } \\
\hline права нирка & 2 & 11,1 & 3 & 16,7 & 1 & 5,6 & 1 & 5,6 & 2 & 11,1 & 3 & 16,7 & 3 & 16,7 \\
\hline ліва нирка & 1 & 5,6 & 4 & 22,2 & 1 & 5,6 & 1 & 5,6 & 3 & 16,7 & 3 & 16,7 & - & - \\
\hline права та ліва нирки & 4 & 22,2 & 1 & 5,6 & 2 & 11,1 & 2 & 11,1 & 3 & 16,7 & 5 & 27,8 & 3 & 16,7 \\
\hline Всього ... & 7 & 38,9 & 8 & 44,5 & 4 & 22,3 & 4 & 22,3 & 8 & 44,5 & 11 & 61,2 & 6 & 33,4 \\
\hline \multicolumn{15}{|l|}{ Сегментарна } \\
\hline \multicolumn{15}{|l|}{ права нирка } \\
\hline $\mathrm{BC}$ & - & - & 1 & 5,6 & 4 & 22,2 & 5 & 27,8 & 1 & 5,6 & 4 & 22,2 & 3 & 16,7 \\
\hline CC & - & - & 1 & 5,6 & 6 & 33,3 & 4 & 22,2 & 8 & 44,4 & 3 & 16,7 & - & - \\
\hline $\mathrm{HC}$ & 1 & 5,6 & 1 & 5,6 & 3 & 16,7 & 2 & 11,1 & 2 & 11,1 & 3 & 16,7 & 3 & 16,7 \\
\hline \multicolumn{15}{|l|}{ ліва нирка } \\
\hline$B C$ & 3 & 16,7 & 2 & 11,1 & 1 & 5,6 & 1 & 5,6 & 1 & 5,6 & 2 & 11,1 & 1 & 5,6 \\
\hline CC & 1 & 5,6 & 2 & 11,1 & 1 & 5,6 & 1 & 5,6 & 1 & 5,6 & 2 & 11,1 & 2 & 11,1 \\
\hline $\mathrm{HC}$ & 3 & 16,7 & 2 & 11,1 & 2 & 11,1 & 2 & 11,1 & 2 & 11,1 & 4 & 22,2 & 3 & 16,7 \\
\hline \multicolumn{15}{|l|}{ права та ліва нирки } \\
\hline$B C$ & 9 & 50 & 12 & 66,7 & 10 & 55,6 & 7 & 38,9 & 12 & 66,7 & 10 & 55,6 & 3 & 16,7 \\
\hline CC & 6 & 33,3 & 9 & 50 & 10 & 55,6 & 7 & 38,9 & 8 & 44,4 & 11 & 61,1 & 1 & 5,6 \\
\hline $\mathrm{HC}$ & 8 & 44,4 & 12 & 66,7 & 9 & 50 & 9 & 50 & 10 & 55,6 & 10 & 55,6 & 6 & 33,3 \\
\hline \multicolumn{15}{|l|}{ Всього ... } \\
\hline$B C$ & 12 & 66,7 & 15 & 83,4 & 15 & 83,4 & 13 & 72,3 & 14 & 77,9 & 16 & 88,9 & 7 & 39,0 \\
\hline CC & 7 & 38,9 & 12 & 66,7 & 17 & 94,5 & 12 & 66,7 & 17 & 94,5 & 16 & 88,9 & 3 & 16,7 \\
\hline $\mathrm{HC}$ & 12 & 66,7 & 15 & 83,4 & 14 & 77,8 & 13 & 72,3 & 14 & 77,9 & 17 & 94,5 & 12 & 66,7 \\
\hline \multicolumn{15}{|l|}{ Міжчасткова } \\
\hline \multicolumn{15}{|l|}{ права нирка } \\
\hline$B C$ & 1 & 5,6 & 1 & 5,6 & 2 & 11,1 & 3 & 16,7 & 2 & 11,1 & 1 & 5,6 & 6 & 33,3 \\
\hline CC & 1 & 5,6 & - & - & 5 & 27,8 & 2 & 11,1 & 5 & 27,8 & 1 & 5,6 & 2 & 11,1 \\
\hline $\mathrm{HC}$ & 1 & 5,6 & 2 & 11,1 & 3 & 16,7 & 4 & 22,2 & 3 & 16,7 & 2 & 11,1 & 2 & 11,1 \\
\hline \multicolumn{15}{|l|}{ ліва нирка } \\
\hline$B C$ & 3 & 16,7 & 1 & 5,6 & 2 & 11,1 & 1 & 5,6 & 1 & 5,6 & 3 & 16,7 & 1 & 5,6 \\
\hline CC & 1 & 5,6 & 3 & 16,7 & 1 & 5,6 & 2 & 11,1 & 3 & 16,7 & 4 & 22,2 & 2 & 11,1 \\
\hline $\mathrm{HC}$ & 3 & 16,7 & 2 & 11,1 & 2 & 11,1 & 3 & 16,7 & 2 & 11,1 & 3 & 16,7 & - & - \\
\hline \multicolumn{15}{|l|}{ права та ліва нирки } \\
\hline$B C$ & 7 & 38,9 & 7 & 38,9 & 9 & 50 & 7 & 38,9 & 10 & 55,6 & 11 & 61,1 & 1 & 5,6 \\
\hline CC & 4 & 22,2 & 3 & 16,7 & 10 & 55,6 & 6 & 33,3 & 8 & 44,4 & 9 & 50 & 1 & 5,6 \\
\hline $\mathrm{HC}$ & 8 & 44,4 & 6 & 33,3 & 9 & 50 & 4 & 22,2 & 9 & 50 & 11 & 61,1 & 4 & 22,2 \\
\hline \multicolumn{15}{|l|}{ Всього ... } \\
\hline$B C$ & 11 & 61,2 & 9 & 50,1 & 13 & 72,2 & 11 & 61,2 & 13 & 72,3 & 15 & 83,4 & 8 & 44,4 \\
\hline CC & 6 & 33,4 & 6 & 33,4 & 16 & 88,9 & 10 & 55,5 & 16 & 88,9 & 14 & 77,9 & 5 & 27,8 \\
\hline $\mathrm{HC}$ & 12 & 66,7 & 10 & 55,5 & 14 & 77,9 & 11 & 61,1 & 14 & 77,9 & 16 & 88,9 & 6 & 33,4 \\
\hline
\end{tabular}

їв Колмогорова - Смирнова, Шапіро - Вілка. Для порівняння середніх значень вибірок, дані яких розподілені за нормальним законом, використовували параметричний t-критерій Ст'юдента. Непараметричні методи (критерії Манна - Вітні, Вальда - Вольфовіца, Колмогорова - Смирнова для непов'язаних груп; критерії знаків, Вілкоксона для пов'язаних груп) використовували для опису розподілу ознаки, що відрізнявся від нормального, або для опису малих вибірок. Отримані результати за нормального розподілу розраховували за допомогою середнього значення та стандартного відхилення $(\mathrm{M} \pm \sigma)$, ненормального розподілу - за допомогою медіани (Ме), 25 і 75 перцентилів (25 - 75\%). Статистично значущими вважали результати, коли рівень статистичної значущості (р) був менше 0,05.

\section{Результати}

У хворих середній систолічний артеріальний тиск (САТ) становив $(169,72 \pm 19,96)$ мм рт. ст., діастолічний (ДАТ) - 100 (90;100) мм рт. ст., рівень альдостеронемії (392,48 $\pm 205,31)$ пг/мл.

Порівняльний аналіз доплерометричних показників не продемонстрував відмінностей між правою та лівою нирками (табл. 1).

У порівнянні з нормативними показниками на рівні стовбура ниркових артерій фіксували зниження Ved на 


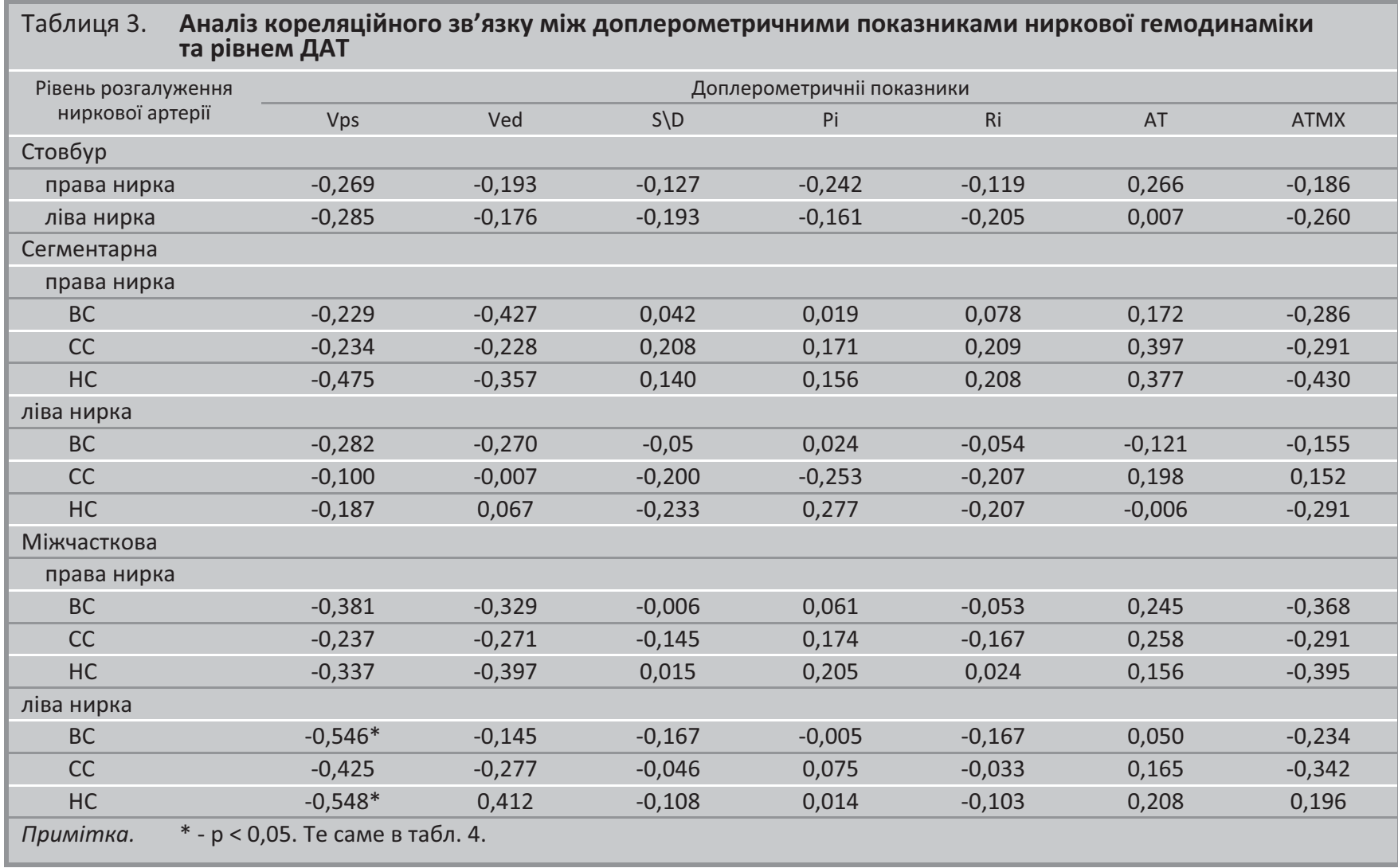

\section{Таблиця 4. Аналіз кореляційного зв'язку між доплерометричними показниками ниркової гемодинаміки та рівнем альдостеронемії}

\begin{tabular}{|c|c|c|c|c|c|c|c|}
\hline \multirow{2}{*}{$\begin{array}{l}\text { Рівень розгалуження } \\
\text { ниркової артерії }\end{array}$} & \multicolumn{7}{|c|}{ Доплерометричні показники } \\
\hline & Vps & Ved & $S \backslash D$ & $\mathrm{Pi}$ & $\mathrm{Ri}$ & AT & ATMX \\
\hline \multicolumn{8}{|l|}{ Стовбур } \\
\hline права нирка & 0,026 & 0,311 & $-0,475$ & $-0,344$ & $-0,423$ & $-0,06$ & 0,196 \\
\hline ліва нирка & $-0,306$ & 0,212 & $-0,403$ & $-0,264$ & $-0,469 *$ & $-0,120$ & 0,126 \\
\hline \multicolumn{8}{|l|}{ Сегментарна } \\
\hline \multicolumn{8}{|l|}{ права нирка } \\
\hline $\mathrm{BC}$ & 0,145 & 0,007 & $-0,154$ & 0,050 & $-0,146$ & $-0,240$ & 0,085 \\
\hline CC & 0,015 & 0,193 & $-0,418$ & $-0,124$ & $-0,376$ & 0,203 & 0,06 \\
\hline $\mathrm{HC}$ & $-0,033$ & 0,102 & $-0,329$ & $-0,055$ & $-0,226$ & 0,158 & 0,027 \\
\hline \multicolumn{8}{|l|}{ ліва нирка } \\
\hline$B C$ & 0,169 & 0,339 & $-0,139$ & $-0,159$ & $-0,296$ & 0,065 & $-0,138$ \\
\hline CC & 0,174 & 0,407 & $-0,439$ & $-0,308$ & $-0,350$ & $-0,007$ & 0,002 \\
\hline $\mathrm{HC}$ & 0,0657 & 0,125 & $-0,349$ & $-0,001$ & $-0,214$ & $-0,191$ & $-0,157$ \\
\hline \multicolumn{8}{|l|}{ Міжчасткова } \\
\hline \multicolumn{8}{|l|}{ права нирка } \\
\hline$B C$ & 0,059 & $-0,04$ & $-0,285$ & 0,016 & $-0,201$ & 0,376 & 0,104 \\
\hline CC & 0,064 & 0,028 & 0,028 & 0,079 & 0,042 & $-0,032$ & $-0,080$ \\
\hline $\mathrm{HC}$ & 0,001 & 0,101 & $-0,253$ & 0,022 & $-0,178$ & 0,209 & 0,013 \\
\hline \multicolumn{8}{|l|}{ ліва нирка } \\
\hline $\mathrm{BC}$ & 0,199 & 0,149 & 0,024 & 0,107 & $-0,036$ & 0,211 & $-0,344$ \\
\hline CC & $-0,183$ & $-0,117$ & 0,025 & 0,103 & $-0,044$ & 0,239 & 0,085 \\
\hline $\mathrm{HC}$ & 0,060 & 0,137 & $-0,486^{*}$ & $-0,360$ & $-0,475$ & 0,074 & $0,692 *$ \\
\hline
\end{tabular}

44,5\%, підвищення АТ на 61,2\% та RI на 44,5\%. Відхилення від референсних значень мали показники АТ у верхньому, середньому та нижньому сегментах нирки на 88,9, 88,9 та 94,5\% відповідно на рівні сегментарних артерій та на 83,4, 77,9, 88,9\% відповідно на рівні міжчасткових артерій, S/D - на 83,4, 94,5 та 77,8\% відповідно на рівні сегмен- 
тарних артерій та на 72,2, 88,9, 77,9\% відповідно на рівні міжчасткових артерій, RI - на 77,9, 94,5 та 77,9\% відповідно на рівні сегментарних артерій та на 72,5, 88,9 та 77,9\% відповідно на рівні міжчасткових артерій, а також РI - на 72,3, 66,7, 72,3\% відповідно на рівні сегментарних артерій та на 61,1, 55,5, 61,1\% відповідно на рівні міжчасткових артерій (табл. 2).

Залежності між показниками САТ у пацієнтів з ПГА та кількісними параметрами стану артеріального кровообігу нирок не виявлено. Однак таку залежність мали показники ДАТ. Зокрема, встановлено кореляційний зв'язок між показниками ДАТ та Vps на рівні міжчасткових артерій у верхньому та нижньому сегментах лівої нирки ( табл.3).

Рівень альдостерону також мав вплив на ниркову гемодинаміку у хворих. Ми виявили залежність між показниками альдостеронемії та RI на рівні стовбура лівої ниркової артерії, S/D та TAMX на рівні міжчасткової артерії нижнього сегмента лівої нирки (табл.4).

\section{Обговорення}

Науковці, які вивчають ниркову гемодинаміку у хворого з ПГА, здебільшого приділяють увагу RI як маркеру ниркового ураження. Y. Iwakura і співавтори встановили, що RI є предиктором післяопераційного показника АТ у хворих з ПГА [7]. За даними L. A. Sechi і співавторів RI у пацієнтів з ПГА перед лікуванням був значно нижчим, ніж після лікування, незалежно від його виду (адреналектомія чи призначення спіронолактону) [8].

Встановлені кореляційні зв'язки між рівнем альдостерону у плазмі крові та показниками RI, S/D i TAMX більш інформативні для практикуючого лікаря, адже вони є кутонезалежними, а отже, більш об'єктивними в оцінці стану ниркової гемодинаміки пацієнтів.

\section{Висновки}

1. Використання ультразвукового доплерівського сканування ниркових артерій у пацієнтів з ПГА є інформативним методом діагностики, адже дає можливість оцінити стан внутрішньониркової гемодинаміки, яка свідчить про ступінь ураження нирок.

2. Показники САТ при ПГА не впливають на стан ниркової гемодинаміки на відміну від ДАТ.

3. Розвиток ПГА у більшості спостережень обумовлює насамперед зміни показників PI, RI та S/D на всіх рівнях розгалуження ниркових артерій.

4. У пацієнтів з ПГА рівень альдостеронемії корелює 3 рядом доплерометричних показників ниркової гемодинаміки, зокрема, RI на рівні стовбура ниркової артерії, S/D та TAMX на рівні міжчасткових артерій.
Підтвердження

Конфлікт інтересів: відсутній.

Інформація про фінансування. Джерелом фінансу-

вання наукової роботи і публікації статті є приватні особи.

\section{Внесок авторів}

Никоненко А. О. - остаточне затвердження статті; Зубрик I. В. - концепція і дизайн дослідження, збирання даних, аналіз та інтерпретація даних, написання статті; Подлужний О. О. - редагування статті; Якименко В. В. - редагування статті.

Всі автори прочитали та схвалили остаточний варіант рукопису.

\section{Конфлікт інтересів}

Автори декларують відсутність конфлікту інтересів.

\section{Згода на публікацію}

Всі автори дали згоду на публікацію цього рукопису.

Етичне твердження. Всі процедури, що проводяться в дослідженнях за участю учасників, відповідали етичним стандартам інституційного та / або національного дослідницького комітету, а також Гельсінкської декларації 1964 року і ії більш пізнім змінам або порівнянним етичним стандартам.

\section{References}

1. Williams TA, Lenders JWM, Mulatero P, Burrello J, Rottenkolber M, Adolf $\mathrm{C}$, et al. Outcomes after adrenalectomy for unilateral primary aldosteronism: an international consensus on outcome measures and analysis of remission rates in an international cohort. Lancet Diabetes Endocrinol. 2017 Sep;5(9):689-99. doi: 10.1016/S2213-8587(17)30135-3.

2. Monticone S, Burrello J, Tizzani D, Bertello C, Viola A, Buffolo Fet al. Prevalence and Clinical Manifestations of Primary Aldosteronism Encountered in Primary Care Practice. J Am Coll Cardiol. 2017 Apr 11;69(14):1811-20. doi: 10.1016/j.jacc.2017.01.052.

3. Rekovets OL, Torbas OO, Kushnir SM, Ponomareva GV, Primak GF, Granich VM, et al. Structure of patients with resistant arterial hypertension. Arteryalnaia hypertenzyia, 2018; 1 (57), 46 - 66. [in Ukrainian]. doi: 10.22141/2224-1485.1.57.2018.125498.

4. Prejbisz A, Warchoł-Celińska E, Lenders JW, Januszewicz A. Cardiovascular Risk in Primary Hyperaldosteronism. Horm Metab Res. 2015 Dec;47(13):973-80. doi: 10.1055/s-0035-1565124.

5. Widimsky J Jr, Strauch B, Petrák O, Rosa J, Somloova Z, Zelinka T, et al.Vascular disturbances in primary aldosteronism: clinical evidence. Kidney Blood Press Res. 2012;35(6):529-33. doi: 10.1159/000340031.

6. Varano M, Iacono P, Tedeschi MM, et al. Comparisons of microvascular and macrovascular changes in aldosteronism-related hypertension and essential hypertension. Sci Rep. 2017 Jun;7(1):2666. doi:10.1038/ s41598-017-02622-2.

7. Iwakura Y, Ito S, Morimoto R, Kudo M, Ono Y, Nezu M, et al. Renal Resistive Index Predicts Postoperative Blood Pressure Outcome in Primary Aldosteronism. Hypertension.2016 Mar;67(3):654-60. doi: 10.1161/ HYPERTENSIONAHA.115.05924.

8. Sechi LA, Di Fabio A, Bazzocchi M, Uzzau A, Catena C. Intrarenal hemo- dynamics in primary aldosteronism before and after treatment. J Clin Endocrinol Metab. 2009Apr;94(4):1191-7. doi: 10.1210/jc.20082245. 